\title{
T1 Slope in the Cervical Spine Magnetic Resonance Imaging: A Novel Concept
}

\author{
Xu Wang \\ Sensory-Motor Interaction, Department of Health Science and Technology, Faculty of Medicine, Aalborg University, Aalborg, Denmark
}

Recently, I read with great interest the paper by Yang et al. [1] titled "The use of T1 sagittal angle in predicting cervical disc degeneration." The objective of this study was to investigate the effects of $\mathrm{T} 1$ slope on the grade of disc degeneration with magnetic resonance imaging (MRI). It provides the idea that patient with lower $\mathrm{T} 1$ slope risks higher grade of disc degeneration.

However, it may lack a validation and reliability study for measurement of T1 slope in MRI. T1 sagittal angle or T1 slope was defined as the angle between a horizontal line and the superior endplate of T1 [2-4]. However, it was defined and measured in radiography. In this paper T1 slope was measured in MRI when the subject was lying in a prone position, which is different from the position when radiography was taken clinically (normally in a standing or sitting position). Although the relationship between disc degeneration and T1 slope measured in MRI warrants the consistency and integration, T1 slope in MRI is different from the one in radiography regarding several reasons, first the cervical alignment may alter when the subject lied, second the selection of MRI frame is different from the lateral radiography, and third bone structure is preferred to be identified by radiography. Thus, a validation and reliability study is needed for measuring T1 slope in MRI before it is further applied.

\section{Conflict of Interest}

No potential conflict of interest relevant to this article was reported.

\section{ORCID}

Xu Wang: https://orcid.org/0000-0003-0029-4398

\section{References}

1. Yang BS, Lee SK, Song KS, et al. The use of T1 sagittal angle in predicting cervical disc degeneration. Asian Spine J 2015;9:757-61.

2. Knott PT, Mardjetko SM, Techy F. The use of the T1 sagittal angle in predicting overall sagittal balance of the spine. Spine J 2010;10:994-8.

3. Kim TH, Lee SY, Kim YC, Park MS, Kim SW. T1 slope as a predictor of kyphotic alignment change after laminoplasty in patients with cervical myelopathy. Spine (Phila Pa 1976) 2013;38:E992-7.

4. Oe S, Yamato Y, Togawa D, et al. Preoperative T1 slope more than $40^{\circ}$ as a risk factor of correction loss in patients with adult spinal deformity. Spine (Phila Pa 1976) 2016;41:E1168-76.

\footnotetext{
Received Dec 22, 2017; Accepted Dec 23, 2017

Corresponding author: Xu Wang

Sensory-Motor Interaction, Department of Health Science and Technology, Faculty of Medicine, Aalborg University,

Fredrik Bajers Vej 7E-2, 9220 Aalborg, Denmark

Tel: +45-9940-8825, Fax: +45-9815-4008, E-mail: x.wang2013@hotmail.com
} 